\title{
Narcisismo Parental e Depressão diante do câncer do(a) filho(a)
}

\author{
Carina Cannavô Alves* \\ Patrícia Paraboni**
}

\begin{abstract}
Resumo
Os casos de câncer entre crianças e jovens têm aumentado, o que gera abalo e necessidade de reorganização subjetiva e relacional em muitas famílias. O objetivo desse artigo é discutir o possível impacto no narcisismo parental do diagnóstico e ameaça de morte do filho acometido de câncer. Para isso foi realizada uma revisão bibliográfica narrativa a partir da qual obtemos resultados que destacam a importância da família como principal cuidador dos pacientes infantojuvenis e o quanto pode ser desestruturador para os pais as perdas geradas pelo adoecimento do filho. A partir disso abordou-se o processo de constituição narcísica, dos ideais e o potencial impacto do diagnóstico de câncer do filho no narcisismo parental. Tais aspectos levaram à temática da crença narcísica e da depressão como um dos possíveis desdobramentos da situação de adoecimento do filho no psiquismo parental.

Palavras-chave: Narcisismo; Depressão; Relações pais-filhos
\end{abstract}

\section{Parental Narcissism and Depression in the Child's Cancer}

\begin{abstract}
Cancer cases amongst children and youth have been rising, unsettling and demanding subjective and relational reorganization within many families. Given this, this paper intends to address the potential effects of a children's oncological diagnosis and risk of death on parental narcissism. It was conducted a bibliographic review, which pointed the family's important role as the main caregiver for young people and how disconcerting can be, to the parents, the losses caused by their children's illness. Then, were approached the processes of narcissistic and ideals constitution and the possible outcomes of the cancer diagnosis on parental narcissism. These aspects led to the subject of narcissistic beliefs and depression as one of the possible consequences of a children's illness on parental psyche.

Keywords: Narcissism; Depression; Parent-Child relations
\end{abstract}

*Psicóloga pela Faculdade Integrada Santa Maria - FISMA

**Dra. em psicologia psicanalítica pela UFRJ e Docente da FISMA. 


\section{Introdução}

A estimativa brasileira para os casos de câncer infantojuvenil $1^{1}$ em 2018 esteve em torno de 12 mil casos. A Agência Internacional para a Pesquisa do Câncer comunicou que em 19 países, entre a década de 1970 e 1990, houve um aumento de $1 \%$ ao ano nos casos infantis e 1,5\% em adolescentes. $O$ índice de sobrevivência também subiu, pois o avanço nas pesquisas oncológicas e as formas de tratamento da doença têm proporcionado sobrevida e até cura (Instituto Nacional de Câncer José Alencar Gomes da Silva [INCA], 2018).

Esse artigo surge da inquietação e necessidade de estudo durante um estágio curricular do curso de Psicologia, no qual nos deparamos com várias situações de crianças e jovens com câncer e percebemos que esses pacientes recebiam a atenção e o devido cuidado, mas seus cuidadores, na sua maioria, familiares, ficavam desassistidos especialmente no que se refere à sua saúde mental. Assim, para entender melhor a complexidade e os aspectos envolvidos nesses casos, realizamos esse estudo.

A bibliografia sobre o câncer infantil aborda o impacto da descoberta do diagnóstico para as famílias. O adoecimento leva os membros da família a uma adaptação inesperada enquanto tentam reajustar seus papéis e responsabilidades. Ao longo do processo de tratamento, realizado muitas vezes longe de casa, as perdas são inúmeras. As modificações nos arranjos domésticos e profissionais alteram o cotidiano, provocando desajuste financeiro, seguidos de angústia, dor, sofrimento e medo (Nascimento, Rocha, Hayes \& Lima, 2005).

Nos estudos psicanalíticos sobre a perda e o luto, encontramos o tema do narcisismo. Freud (1914/1996) concebe o narcisismo como constitutivo do sujeito a partir da relação parental/cuidadores. A condição neotênica do infante comporta dependência e, ao mesmo tempo, abarca a promessa do ressurgimento do narcisismo perdido dos pais, preenchendo-os de esperança quanto a um futuro cheio de alegria e sucesso para o novo ser que se apresenta. A criança é protegida da dor e do sofrimento pelos pais, os quais negam que o filho sofrerá restrições e passará pelas tristezas da vida (Bemgochea, Junior \& Medeiros, 2017).

$\mathrm{O}$ que acontece quando um terceiro elemento aterrador, chamado câncer, começa a fazer parte dessa rela-

\footnotetext{
Ao longo do artigo vamos utilizar duas terminologias: câncer infantil e câncer infanto-juvenil, pois durante a produção da pesquisa atualizações no principal site de referência para o câncer no Brasil (INCA) foram observadas. Outros materiais de referência, anteriores ao ano de 2019, utilizam o termo câncer infantil. Optamos, assim, por intercalar o uso destes dois termos.

ção? Quando a substância essencial para o renascimento narcísico, a esperança futura, fica ameaçada? E quando o depositário dessa expectativa vindoura não tem mais condições físicas e psíquicas de sustentar o narcisismo renascido dos pais? Com base nessas questões, o objetivo do artigo foi refletir sobre o impacto no narcisismo parental do diagnóstico e ameaça de morte do filho acometido de câncer.

Para realizar o objetivo proposto foi utilizado o método bibliográfico com revisão narrativa da literatura. Esse tipo de pesquisa permite conhecer uma gama de fenômenos e informações mais amplas, podendo atingir sua abrangência nas experiências e pesquisas publicadas sobre o tema em questão (Gil, 2018).

As palavras utilizadas para a busca em plataformas online foram: narcisismo, psicanálise, pais, câncer infantil. Dentre as bases de dados utilizadas para esta revisão, situam-se as publicações nas áreas de saúde e psicologia: SciELO (Scientific Electronic Library Online) e Pepsic (Periódicos Eletrônicos de Psicologia). Os critérios de inclusão foram as publicações completas de periódicos nacionais, no idioma português, que incluíam as palavras acima citadas, sem data estabelecida e que tinham o viés psicanalítico. Foram excluídos os artigos em língua estrangeira e que não contemplavam os critérios de inclusão. Além dos artigos, outros textos e livros encontrados sobre o tema e que contemplavam o objetivo proposto foram utilizados.

Assim, a investigação seguiu as etapas de leitura exploratória a partir do qual avaliamos se a obra consultada estava de acordo com os critérios de inclusão e objetivo da pesquisa. Após seguimos com a leitura analítica, na qual foram selecionados os materiais da etapa anterior e o trabalho foi direcionado para ordenar e sumariar as informações das fontes. $\mathrm{Na}$ sequência, foi realizado o fichamento que é a organização em registros (fichas) das obras analisadas. No fichamento foi registrada a identificação da obra consultada, seguida de anotações das ideias decorrentes da leitura, conteúdos relevantes, comentários acerca das obras e informações que interessavam a essa investigação (Gil, 2018).

Conforme avançavam as leituras e fichamentos, outros textos foram selecionados a partir das referências utilizadas. Logo após o fichamento procedemos à leitura interpretativa intercambiando conhecimentos e relacionando com autores que trouxeram uma aproximação do problema proposto na pesquisa (Gil, 2018). Por fim, foi realizada a elaboração e escrita do presente artigo. Diante disso, no que segue apresentamos os principais aspectos encontrados de acordo com o objetivo proposto para esse 
estudo. Dentre os resultados encontrados e que serão apresentados a seguir, foi possível compreender que o diagnóstico de câncer do filho pode sinalizar a derrocada dos ideais e desejos dos pais, abalando seu narcisismo e, em alguns casos, pode levar à depressão.

\section{Impactos do diagnóstico de câncer na família}

Existem muitos conceitos para definir família e para Osório (1997) a família é uma unidade de interação social que através dos tempos tomou formas e mecanismos diferentes. Trata-se do primeiro grupo do qual o indivíduo faz parte. A constituição familiar coexiste hoje sobre princípios morais e psicológicos diversos, contraditórios e inconciliáveis. A estrutura familiar varia ao longo do tempo segundo referências religiosas, econômicas, históricas e sociopolíticas, sempre levando em consideração a cultura. Nesse sentido, cabe à psicanálise, analisar a estrutura familiar existente em cada situação e contexto para identificar as coordenadas do desejo inconsciente que a determina (Lopes \& Santos, 2017).

A situação "neotênica" da espécie humana, que é a impossibilidade de sua descendência sobreviver sem cuidados ao longo dos primeiros anos de vida, foi responsável pelo surgimento do núcleo familiar como agente de perpetuação da vida humana. A família se torna, então, a estrutura responsável por garantir a sobrevivência da espécie. Sendo assim, propicia a matriz para o desenvolvimento psíquico dos descendentes e aprendizagem da interação social. A partir dos objetivos genéricos de preservar as espécies, nutrir, proteger a descendência e fornecer as condições para a aquisição de suas identidades pessoais (Osório, 1997).

O papel da família de preservar e cuidar de seus filhos, os laços afetivos que os pais desenvolvem com eles e a efemeridade humana, revelada pela vulnerabilidade imposta pelo câncer infantojuvenil, coloca a família diante da ameaça do término abrupto da vida, invertendo a ordem natural de sua finitude. $\mathrm{O}$ câncer, assim, invade o espaço familiar e revela não só a fragilidade, mas também a situação afetiva e social da família (Dousset, 1999).

Geralmente os pacientes em tratamento de câncer necessitam acompanhamento. No caso do câncer infantojuvenil as famílias são mobilizadas para oferecer apoio à criança. O momento do diagnóstico de câncer infantil é percebido pelos pais como um desestruturador familiar. Um evento potencialmente catastrófico ligado ao ideário de morte. Apesar dos avanços na área médica e farmacológica, os pais de criança em tratamento ainda continuam expostos a situações de sofrimento emocional por períodos prolongados. Dentre as principais causas desse sofrimento estão: a hospitalização de longa duração, a terapêutica medicamentosa (com seus efeitos colaterais desagradáveis), a separação dos membros da família durante as internações, a interrupção das atividades cotidianas, a renúncia do emprego dos pais, a interrupção dos estudos da criança, desajustes financeiros, episódios de angústia, dor e medo diante da possibilidade de morte do filho (Mensorio, Kohlsdorf \& Costa Junior, 2009; Nascimento, Rocha, Hayes \& Lima, 2005; Cardoso, 2007).

Ao receber a notícia do diagnóstico as famílias experimentam um forte abalo decorrente da situação inesperada, o que favorece o sentimento de angústia, sendo que a notícia abrupta pode desencadear um traumatismo psíquico. Diante disso, surge o sentimento de impotência e desamparo, no qual o sofrimento é seguido de passividade ou fuga. A notícia do diagnóstico traz consigo o estigma associado ao sofrimento intenso pelo qual passará o paciente e, talvez, sua posterior morte (Almeida \& Santos, 2013).

A angústia é um dos principais afetos que acometem os pais. Trata-se de um afeto diante daquilo que o sujeito não pode articular e que é muito difícil de ser representado e simbolizado. Momento que desorienta, desampara e faz com que os pais de crianças com câncer sintam-se perdidos (Almeida \& Santos, 2013). Vale ressaltar que nem todos reagem da mesma maneira.

Para Kübler-Ross (2017) existem fases ou estágios de adaptação em relação à descoberta do câncer. No primeiro estágio as famílias não acreditam que seja verdade, contudo procuram outros médicos, solicitando novos exames. Não para confirmar o diagnóstico, todavia para ouvir que o primeiro diagnóstico pode ter sido um erro médico. $\mathrm{Na}$ fase seguinte as famílias dirigem hostilidades e raiva aos médicos que comunicam o diagnóstico e aos que examinaram o doente; e projetam sua fúria nos funcionários do hospital. Sentem, ainda, culpa e desejo de recuperar oportunidades do passado.

Após a presença do ressentimento, da raiva e da culpa, a família entra na fase do pesar preparatório. Quanto mais conseguirem vivenciar e lidar com o pesar antes da morte, maiores são as possibilidades de suportar a perda depois. Se os membros de uma família podem juntos compartilhar emoções que permeiam esse processo, enfrentarão depois aos poucos a realidade da separação iminente e poderão aceitá-la. Com isso, podem ir vivenciando a perda gradualmente preparando-se para a morte (Kübler-Ross, 2017). 
As pesquisas sobre temas relacionados ao câncer infantil e aos familiares que participam ativamente do processo de tratamento, como os cuidadores mais próximos, no caso o pai e a mãe, não é incomum encontrar inúmeros relatos na literatura que salientam os sentimentos que tomam conta dos pais nesse período. Dentre esses sentimentos, autores destacam as incertezas do curso da doença, o medo da morte e da recidiva do câncer (Menezes, Passarei, Drude, Santos \& Valle, 2007; Oliveira, Santos, Marinho, Cordeiro, Salge \& Siqueira, 2010; Campos, Rodrigues, Machado \& Alvarez, 2007; Duarte, Zanini \& Nedel, 2012; Castro, 2010).

Os sentimentos ambíguos acerca da quimioterapia, ora parecem devolver a vida para a criança, ora intensificam o medo da morte e das recidivas. Duarte, Zanini e Nedel (2012) destacaram a importância da compreensão dos sentimentos de "impotência diante da criança doente, a sensação de insuficiência, a expectativa de morte e a descrença nas medidas terapêuticas disponíveis e refletem um tipo de paralisia diante da situação" (p. 115). A angústia diante da percepção de que o câncer pode levar à morte independente dos esforços, torna mais evidente os sentimentos vivenciados pelos pais. Os autores ainda afirmam que esses pensamentos abalam as estruturas familiares e proporcionam que seus membros repensem a sua própria existência.

A angústia dos pais não recai somente sobre o sofrimento do próprio filho, mas Castro (2010) acrescenta que os outros pequenos pacientes internos do hospital, também mobilizam pais e mães de outras crianças. A dor compartilhada naquele ambiente é tamanha que muitos deles expressam que desejam trocar de lugar com o filho.

Os pais passam pelo processo do tratamento de câncer infantil com receio da morte dos filhos. Esse sofrimento chega ao ponto de sentirem seu próprio narcisismo ameaçado pela possibilidade de perda daquele que é uma parte de si e carrega a sua revivescência. Todo investimento libidinal dispensado pelos pais aos filhos e todo o projeto daquilo que nem mesmo os pais puderam alcançar é depositado nos pequenos. O câncer, porém, é implacável. Não no sentido extremo e terminal que resulta em morte, mas no sentido de paralisia e intimidação da vida, ficando tudo em suspenso, inclusive os investimentos narcísicos que agora se voltam novamente para os cuidados, especialmente com o corpo da criança (Góes, 2013).

\section{Narcisismo perdido e narcisismo renascido}

O conceito de narcisismo é desenvolvido por Freud (1914/1996) em seu texto Sobre o narcisismo: uma introdução.
Freud (1914/1996) concebe o narcisismo como a atitude de uma pessoa que se ocupa ou interessa-se pelo próprio corpo da mesma maneira como poderia tratar de se ocupar ou interessar-se pelo corpo de outrem como objeto sexual. Este objeto sexual comumente contemplado, afagado, acariciado serve para que se obtenha satisfação completa. O narcisismo seria, então, o ato de provocar tais sensações em si mesmo, adquirindo com isso satisfação de si para si. Além disso, o autor afirma que na atitude narcísica estaria presente o complemento libidinal do egoísmo da pulsão de autopreservação. O narcisismo vem a ser a atitude de voltar para si a libido que antes era dirigida ao mundo externo.

Freud (1914/1996) afirma que o ego, enquanto unidade, não existe desde o início, mas tem de ser desenvolvido. Para que o narcisismo advenha será necessária uma nova ação psíquica, a qual deve ser adicionada ao autoerotismo. O autor levanta a hipótese de ter havido desde o início uma separação entre pulsões sexuais e outras pulsões do ego. Além disso, considera que o indivíduo leva uma existência dúplice: uma para servir às suas próprias finalidades e outra como um elo em uma corrente. No sentido de que os pais sobrevivem através dos filhos, o que esboça a ideia de imortalidade.

Segundo o autor a atitude afetuosa dos pais para com os filhos é como uma revivescência e reprodução de seu próprio narcisismo. $\mathrm{Na}$ distante infância dos pais a libido do ego retornava a eles e tinham a impressão de serem onipotentes. Eles criaram há muito tempo a fantasia de satisfação plena, de vontade prontamente atendida. Acontece que por época do Complexo de Édipo e do fenômeno da castração, os que agora são pais, começaram a compreender que a realidade se impõe sobre toda a vontade humana e que o custo para a vida em sociedade é a adequação às regras colocadas por ela (Freud, 1914/1996).

No decorrer do desenvolvimento adulto, a libido que antes era investida em si mesmo é reinvestida nos filhos. Ela se torna assim libido objetal. Mas ainda reverbera na memória dos pais o sentimento megalomaníaco, tão próprio do narcisismo, em forma de expectativas que não poderão, também, na sua totalidade serem satisfeitas pelos filhos (Freud, 1914/1996).

Pinheiro $(1995$, p.1) se refere ao narcisismo como a "invenção de dois adultos - os pais da criança ou daqueles que dela se ocupam". A autora descreve que o aparelho psíquico da criança passa por "um longo e complexo processo de assimilação" que vai desde os sonhos dourados dos pais, pensados para a criança que chega, até 
as imposições sociais que obrigam o aparelho psíquico, em desenvolvimento, a se reorganizar. O aparelho egóico compreende uma pluralidade de EUs que são meios necessários à aceitação da castração.

Freud (1914/1996) se refere a "sonhos dourados" (Freud, 1914/1996, p. 98) como uma atitude emocional de supervalorização, na qual os pais acham que o filho é perfeito, ocultando e esquecendo todas as deficiências deles. Para os filhos não faltará investimentos, seus pais vão supervalorizar e suprir as necessidades da vida, sendo que a doença, a morte, a renúncia ao prazer e restrições à vontade não serão empecilhos para os pequenos reis, coroados pelos pais. O filho será o centro da criação, portanto, "sua majestade o bebê". Assim, a criança concretizará "os sonhos encantados" dos pais, no ponto mais sensível, a imortalidade do ego. Tão oprimida pela realidade, a segurança será alcançada por meio do refúgio na criança. $\mathrm{O}$ amor dos pais nada mais é que o narcisismo dos pais renascido, o qual, transformado em amor objetal revela sua natureza original.

A época presente trouxe alterações quanto à organização das famílias com a chegada de um novo membro. Alguns casais costumam escolher o nome da criança logo após a ultrassonografia revelar o sexo do bebê. $\mathrm{Na}$ sequência já começam as compras do berço, do carrinho, das roupinhas e uma série de desejos e aspirações são projetadas no novo membro da família. Assim começam as idealizações e os desejos sendo inscritos na criança e marcando sua constituição psíquica. O evento do nascimento é um momento de expectativa e inquietação, pois inscreve na realidade a imortalidade do ego dos pais, com o qual cada um nega a finitude da vida e procura perpetuar-se pela eternidade. O filho é a esperança de realização de seus desejos (Góes, 2006).

Ao nascer a criança ainda não é um sujeito psíquico. Todo o preparo que antecede o seu nascimento e as expectativas colocadas nela irão contribuir para a formação desse sujeito que é necessariamente vinculado à presença de um outro - pais ou cuidadores. Esse outro (parental) precisa primeiramente investir libidinalmente a criança, para que ela pouco a pouco comece a perceber suas fronteiras físicas e psíquicas (Moraes \& Macedo, 2011).

A importância do movimento identificatório no processo de construção de si mesmo está presente na descrição do narcisismo, o qual depende da qualidade das relações existentes entre o eu e seus objetos de investimento. Nesse sentido o que é oferecido pelo objeto externo terá papel decisivo na configuração da imagem de si. Há uma importante relação entre o que será projetado como ideal da criança e as condições narcísicas dos pais (Moraes \& Macedo, 2011).

O ser humano uma vez que experimenta a satisfação completa, aquela que se dá quando seu corpo frágil é erogenizado libidinalmente, alimentado e cuidado, sendo tratado como uma majestade para a qual nada falta, tem dificuldade em abrir mão dessa vivência. Essa satisfação já desfrutada torna-se empecilho para a renúncia posterior que ele precisará fazer para conviver em sociedade. O conceito de eu ideal está ligado a uma memória desse período da qual o ser humano resiste em desvencilhar ou renunciar de seu lugar de majestade e onipotência narcísica (Moraes \& Macedo, 2011).

O eu ideal ou ego ideal é a representação imaginária de uma posição superlativa absoluta, dotada da onipotência de que desfruta a "Sua Majestade o Bebê" (Freud, 1914/1996, p. 98) na infância, sem medos, sem castração, sem regulação pelo outro ou pelo mundo da cultura. Trata-se de uma formação intrapsíquica que segundo Laplanche e Pontalis (2016) outros autores pós freudianos escolheram chamar de ideal narcísico de onipotência, pois seria forjado a partir do modelo do narcisismo infantil.

Segundo Laplanche e Pontalis (2016) Freud (1914/1996; 1923/1996) não fez nenhuma distinção conceitual entre eu ideal e ideal de eu, mas depois dele "certos autores retomaram o par formado por estes termos para designarem duas formações intrapsíquicas diferentes" (Laplanche \& Pontalis, 2016. p.222-223). Freud (1914/1996) apenas introduziu o termo eu ideal designando que na origem da formação das instâncias ideais de personalidade o sujeito coloca como objetivo, para ele mesmo, retornar ao estado de onipotência do narcisismo infantil. Nesse sentido, o eu ideal é sempre inerente a onipotência (Laplanche \& Pontalis, 2016).

O ideal de eu ou do ego está mais ligado ao referencial simbólico em conformidade com os valores herdados das instâncias parentais e da sociedade em geral. Podemos dizer que ele está sempre em relação a um outro (Kaufmann, 1996). O ideal do ego resulta da convergência do narcisismo (idealização do eu/ideal de eu) e das identificações parentais, com seus substitutos e com os ideais coletivos. Além disso, é um modelo a que o sujeito procura conformar-se (Laplanche \& Pontalis, 2016).

$\mathrm{O}$ que o homem projetaria diante de si como "seu ideal - é o substituto do narcisismo perdido da infância; nesse tempo o seu próprio ideal era ele mesmo" (Laplanche \& Pontalis, 2016, p.222). O ideal de eu procura resgatar o que ficou interditado no sujeito através do processo civilizatório. As interdições decorrentes do 
aprendizado cultural de cada indivíduo operam a função da castração que dita as regras, polindo ou socializando para o bom convívio. O sujeito recorre ao ideal de eu para retomar o que foi perdido por essas interdições. Neste sentido o ideal de eu ao tentar essa reconquista, no caso os pais em relação aos filhos, precisa convocar um outro a ser um duplo na repetição de sua história (Moraes \& Macedo, 2011).

A esperança dos pais coloca os filhos no lugar de substituição simbólica de seu narcisismo primário. É importante ressaltar que o ego ideal sofre uma transformação ao longo da constituição psíquica, ele acaba tendo que se moldar de acordo com o que é valorizado socialmente ou permitido, abdicando da onipotência, dando origem ao ideal de eu. Os pais encontram-se no registro do ideal de eu e estão sempre a lidar com a frustração de não ser aquilo que projetaram como idealização (eu ideal), transferindo para os filhos a recuperação do eu ideal, o qual precisaram abandonar (em parte) para a vida em sociedade (Laplanche \& Pontalis, 2016).

Os filhos tornam-se detentores da imagem idealizada dos pais. Trata-se de seu ego ideal fixado e projetado agora nos filhos, o qual revela e remete ao que os pais gostariam de ter sido. Quando o indivíduo não consegue realizar-se, tende a fazer grandes investimentos naquilo “[...] que possui a excelência que falta ao ego para torná-lo ideal [...]" (Freud, 1914/1996, p.107). No imaginário dos pais os filhos poderão reproduzir na íntegra a experiência de satisfação sentida no seu narcisismo primário (Garcia-Roza, 1984).

Os filhos são na verdade sentidos como uma parte de si mesmo. Talvez seja essa a constatação freudiana quando ele comenta que "[...], pois cada um desses antes" amados era afinal de contas uma parte de seu próprio eu amado [...]" (Freud, 1915/1996, p. 303) ${ }^{3}$. Desse modo, o nascimento dos filhos aflora nos pais expectativas sobre a imortalidade do ego revivida no novo ser, sendo a finitude negada. Por outro lado, ao se depararem com situações ameaçadoras a vida dos filhos defrontam-se, talvez de uma maneira mais radical, com a incompletude e o fato da impossibilidade de alcançar novamente seu narcisismo perdido da infância.

O câncer deixa os pais impotentes frente a uma doença de difícil combate. Essa perspectiva duvidosa de cura faz esmorecer toda significação antes atribuída aos filhos e

Embora a palavra "antes" do trecho acima citado, possa, na frase, sugeri uma substituição pela palavra "entes" de "entes amados” a citação, assim, descrita está fiel ao texto em português referenciado.

3 O trecho citado referia-se quando da morte de pessoas próximas. leva a uma concentração de forças em prol de sua recuperação, o que reverbera também na tentativa de recuperar seu próprio narcisismo perdido, dentre outros aspectos.

\section{Crença narcísica e depressão parental}

No caso dos pais que estão sob constante ameaça de perda dos filhos, alguns podem experimentar diversos lutos. Não apenas em relação à morte da criança, mas de todo o entorno que havia sido construído e que se perdeu/modificou em função da doença. No câncer infantil a doença vai "carcomendo" a vida em seus mais variados aspectos. Perdas e lutos são vividos diariamente, em relação a diversos fatores da vida, inclusive, em relação ao ideal que foi projetado no filho, o qual é dotado da promessa de imortalidade dos pais.

Entretanto, diante do câncer do filho, o ponto mais vulnerável do sistema narcísico dos pais, “[...] a imortalidade do eu" fica encurralada e "sofre com a reedição de uma imensa ferida narcísica" (Taborda, 2017, p.15) que se refere à vulnerabilidade e finitude humana que a ilusão narcísica tenta recobrir. Seguindo essa linha de pensamento, vamos abordar a noção de crença narcísica que traz em seu bojo teórico as concepções de imortalidade do eu e onipotência original.

Segundo Pinheiro, Quintella e Verztman (2010) a crença narcísica designa o ponto do ideário infantil no qual o discurso dos pais é introjetado pela criança sustentando a ilusão de uma onipotência original, ou seja, um investimento muito alto em ideias de imortalidade e onipotência do eu. Tal situação gera no indivíduo que o recebe uma certeza no amanhã capaz de lhe conferir esperança para continuar investindo na vida. "Este eu narcísico, portanto, nasce de uma ficção, montada na fantasia de um objeto complementar que traria a plenitude perdida" (Pinheiro, 1995, p.2).

A crença narcísica faz parte da formação do eu ideal. Ela funda a relação do sujeito com sua própria imagem ideal, característica do mito de onipotência infantil, participando da formação e constituição do sujeito. Esta formação psíquica do infante conta com os investimentos parentais e com os discursos idealizados por eles: a criança que chega deve ser perfeita e não passará pelos sofrimentos que seus pais experimentaram (Pinheiro, Quintela \& Vertzman, 2010).

Tendo em vista essas questões, apoiados em Pinheiro, Quintella e Verztman (2010), entendemos que o câncer do filho poderia levar os pais a um estado de depressão que difere do luto e da melancolia. Segundo os autores a apresentação sintomática da depressão está ligada a uma 
perda de "condição ideal impedida de transformação". Isso quer dizer que os pais, ao se identificarem narcisicamente com os filhos, podem desenvolver a depressão em decorrência da impossibilidade de recuperação de seu eu ideal projetado na criança doente de câncer.

Os pais das crianças com câncer vivenciam, durante o processo de tratamento, várias perdas que incluem: a rotina que tinham, a casa (pois eles passam muito tempo em hospitais ou casas de apoio), o trabalho, o convívio com os outros filhos, com os cônjuges, os vínculos sociais, dentre outros. Diante das perdas pode se dar o trabalho do luto. De acordo com Pinheiro, Quintella e Verztman (2010) o trabalho do luto consiste na elaboração e assimilação psíquica da perda, permitindo a separação do objeto perdido e o reinvestimento em um substituto. Tal trabalho possibilita que a dor não se eternize e ocorra o desligamento do objeto, mesmo que isso implique num processo lento e demorado. Nos casos específicos que estamos tratando nesse artigo, entendemos que esse trabalho do luto em relação a alguns objetos será realizado para que o investimento libidinal seja direcionado para o cuidado com o filho doente.

Entretanto, paralelamente a esse trabalho de luto em relação a alguns objetos, sobrevém a dificuldade e talvez a impossibilidade de lidar psiquicamente com a perda dos ideais projetados no filho com câncer. A depressão seria a forma do sujeito situar-se diante da perda. A presença predominante da crença narcísica na vida psíquica faz com que seja muito difícil lidar com a ideia da finitude, por isso pode advir a depressão. Esta revela um sofrimento marcado pela dificuldade de elaborar sua própria condição transitória (Pinheiro, Quintella \& Verztman, 2010).

O deprimido sabe o que o aflige, o que está perdido, se depara com a imagem de si perdida e impedida de transformação. No entanto, defensivamente, o sujeito nega a morte de seu narcisismo e se refugia na crença narcísica, na busca pelo retorno da onipotência do eu. Portanto, na depressão não há lugar para o trabalho do luto, mas o protesto contra a perda de si, da imagem perfeita subjugada pelo assombro de sua própria transitoriedade. Nesses casos o ideal do eu se confunde com o eu ideal (Pinheiro, Quintella \& Verztman, 2010).

O tempo e as frustrações decorrentes da não correspondência dos filhos com câncer aos sonhos dourados dos pais vai formando um novo ideal de eu, que resgatando aspectos da realidade, exige uma nova ação psíquica que não o luto, pois a interferência da crença narcísica não permite que este seja elaborado. Deste modo resta ao aparato psíquico parental a imobilidade diante de uma situação sem saída que figura mais como uma "imagem parada", "imagem centralizada de si" (Pinheiro, Quintella \& Verztman et al., 2010).

A angústia, como vimos anteriormente, é o principal sentimento que acomete os pais durante a descoberta do diagnóstico. A desestruturação sofrida nesse período e as perdas decorrentes do longo processo de tratamento podem acarretar quadros depressivos com profundo sentimento de perda. Atrelado a isso os tratamentos contemporâneos na área oncológica têm avançado a ponto de elevar as estatísticas de sobrevida e tem esperançado cada vez mais os pais. Por outro lado, sabemos que devido à subjetividade de cada indivíduo nem todos reagem da mesma forma. Alguns, porém, podem desenvolver um tipo de depressão que difere do luto e da melancolia como encontrado no texto de Pinheiro, Quintella e Verztman (2010). Esta depressão postulada por eles representa o cerne do discurso depressivo dos pais que tem uma imagem de si perdida e que foi projetada no filho.

Alguns pais não iniciam o processo de elaboração do luto, visto que não conseguem deparar-se com a condição de transitoriedade. Portanto, ao não destituir a crença narcísica com a instauração do ideal do eu e ao negar o desejo que faz investir e a finitude daquilo que passa, resta aos pais de filhos vítimas do câncer infantojuvenil deprimir. Em razão de que a depressão é a negação da morte de seu narcisismo. Esta depressão é tida como uma saída defensiva e um lamento pela perda de si.

\section{Considerações finais}

A contemporaneidade tem trazido formas de subjetivação com enfoque nas questões narcísicas. Com isso fomos levados a pensar em como a substância essencial para o renascimento narcísico dos pais nos filhos responde a um tipo de doença grave como o câncer que pode levar a morte. Diante dessa questão, entendemos que muitos pais, assolados pela interferência da crença narcísica não conseguem elaborar os lutos na forma de um processo. Talvez por isso possa advir a depressão como uma forma de reação às inúmeras perdas e ameaças de perda que atravessam suas vidas ao longo do câncer dos filhos.

Entretanto, muitas questões ainda devem ser investigadas como os casos em que os pais não conseguem investir mais nos filhos, situações de luto antecipatório. Ainda seria preciso problematizar de forma mais aprofundada a relação da depressão parental com o investimento nos cuidados com o filho acometido de câncer. Enfim, as situações e respostas psíquicas dos pais e do ambiente ao 
adoecimento da criança e do adolescente podem ser as mais diversas, nesse trabalho apenas elencamos a questão do narcisismo e da depressão como uma das possibilidades de se pensar essa situação tão complexa.

\section{Referências}

Almeida, M. D., \& Santos, A. P. A. L. (2013). Câncer infantil: o médico diante de notícias difíceis-uma contribuição da psicanálise. Mudanças-Psicologia da Saúde, 21(1), 49-54. Recuperado de https://www.metodista.br/revistas/revistas-ims/index.php/MUD/article/download/4060/3645 $+\& \mathrm{~cd}=1 \& \mathrm{hl}=\mathrm{pt}-$ $-\mathrm{BR} \& \mathrm{ct}=\mathrm{clnk} \& \mathrm{gl}=\mathrm{br}$.

Bemgochea Junior, D. P., \& Medeiros, M. P. (2017). Meu filho não merece sofrer: o narcisismo parental na contemporaneidade. Leitura Flutuante. Revista do Centro de Estudos em Semiótica e Psicanálise, 9(1), 45-60. Recuperado de https://revistas.pucsp.br/leituraflutuante/article/view/32800

Instituto Nacional de Câncer José Alencar Gomes da Silva. Estimativa 2018: incidência de câncer no Brasil. Rio de Janeiro: INCA, 2017. Recuperado de http://www1.inca.gov.br/estimativa/2018/.

Campos, E. M. P., Rodrigues, A. L., Machado, P. \& Alvarez, M. (2007). Intervenção em grupo: experiência com mães de crianças com câncer. Psicologia em Estudo, 12 (3), 635-640. Recuperado de http://www.scielo.br/pdf/pe/ v12n3/v12n3a21.pdf.

Cardoso, F. T. (2007). Câncer infantil: aspectos emocionais e atuação do psicólogo. Revista da SBPH, 10(1), 25-52. Recuperado de http://pepsic.bvsalud. org/scielo.php?script=sci_arttext\&pid=S1516-08582007000100004\&lng $=$ pt\&nrm $=$ iso.

Castro, E. H. B. (2010). A experiência do câncer infantil: repercussões familiares, pessoais e sociais. Revista Mal-estar e Subjetividade, 10(3), (971-994). Recuperado de http://pepsic.bvsalud.org/pdf/malestar/v10n3/13.pdf.

Dousset, M.-P. (1999). As relações entre os doentes e os familiares. In DOUSSET, M.-P. Vivendo durante um Câncer, (pp. 181-199). Bauru: Edusc.

Duarte, M.de. L.C., Zanini, L.N., Nedel, M. N.B. (2012). O cotidiano dos pais de crianças com câncer e hospitalizadas. Revista Gaúcha de Enfermagem, 33 (3), 111-118. Recuperado de https://www.seer.ufrgs.br/RevistaGauchadeEnfermagem/article/viewFile/21342/21953

Freud, S. (1996). Sobre o narcisismo: uma introdução. In Edição Standard Brasileira das Obras Completas de Sigmund Freud (J. Salomão, trad.) (Vol.14, pp.76-108). Rio de Janeiro, RJ: Imago. (Original publicado em 1914).

Freud, S. (1996). Reflexões para os tempos de guerra e morte. In Edição Standard Brasileira das Obras Completas de Sigmund Freud (J. Salomão, trad.) (Vol. 14, pp. 299-312). Rio de Janeiro, RJ: Imago. (Original publicado em 1915).

Freud, S. (1996). O ego e o id. In Edição Standard Brasileira das Obras Completas de Sigmund Freud (J. Salomão, trad.) (Vol. 19, pp. 15-80). Rio de Janeiro, RJ: Imago. (Original publicado em 1923).

Garcia-Roza, L. A. (1984). Freud e o inconsciente. Rio de Janeiro: Jorge Zahar Editor Ltda.

Gil, A. C. (2018) Como elaborar projetos de pesquisa. São Paulo: Atlas.

Góes, A. P. F. (2013). A ética e a ameaça de morte em crianças com câncer. Dissertação de mestrado, Universidade Católica de São Paulo, PUC-SP,
São Paulo, SP. Recuperado de https://sapientia.pucsp.br/bitstream/handle $/ 15270 / 1 /$ Ana $\% 20$ Paula $\% 20$ Faulhaber $\% 20$ Goes.pdf.

Góes, F. A. D. B. (2006). Um encontro inesperado: os pais e seu filho com deficiência mental. Psicologia: ciência e profissão, 26(3), (pp.450-461). Recuperado de http: / / www.scielo.br/scielo.php?script=sci_arttext\&pid=S1414-98932006000300009\&lng=en\&nrm=iso

Kaufmann, P. (1996). Dicionário enciclopédico de psicanálise: o legado de Freud e Lacan. Rio de Janeiro, RJ: Jorge Zahar Ed.

Kübler-Ross, E. (2017). Sobre a morte e o morrer: O que os doentes terminais têm para ensinar a médicos, enfermeiras, religiosos e aos seus próprios parentes. (pp.7). São Paulo, SP: WWF Martins Fontes.

Laplanche, J. \& Pontalis, J. B. (1988). Vocabulário da psicanálise. São Paulo, SP: Martins Fontes.

Lopes, R. G., \& Santos, T. C. (2017) Somos todos adotados? Parentalidade, família e filiação. Cadernos de Psicanálise, SPCRJ,33 (1), 63-71. Recuperado de https://spcrj.org.br/ojs/index.php/cad_psi_spcrj/article/view/22/33

Menezes, C. N. B., Passareli, P. M., Drude, F. S., dos Santos, M. A., \& do Valle, E. R. M. (2007). Câncer infantil: organização familiar e doença. Revista Subjetividades, 7(1), 191-210. Recuperado de http://pepsic.bvsalud.org/scielo. php? script $=$ sci_arttext\&pid $=$ S1518-61482007000100011.

Mensorio, M. S., Kohlsdorf, M., \& Costa Júnior, Á. L. (2009). Cuidadores de crianças e adolescentes com leucemia: análise de estratégias de enfrentamento, Psicologia em Revista, 15(1), 158-176. Recuperado de http:// periodicos.pucminas.br/index.php/psicologiaemrevista/article/view/622

Moraes, E. G. \& Macedo, M. M. K. (2011). Vivência de indiferença: do trauma ao ato-dor. São Paulo, SP: Casa do Psicólogo.

Nascimento, L. C., Rocha, S. M. M., Hayes, V. H., \& Lima, R. A. G. D. (2005). Crianças com câncer e suas famílias. Revista da Escola de Enfermagem da USP, 39(4), 469-474. Recuperado de http://www.scielo.br/pdf/reeusp/ v39n4/13.pdf.

Oliveira, R. R., Santos, L. F., Marinho, K.C., Cordeiro, J. A. B. L., Salge, A. K. M. \& Siqueira, K. M. (2010). Ser mãe de um filho com câncer em tratamento quimioterápico: uma análise fenomenológica. Ciência, Cuidado e Saúde, 9 (2), 374-382. Recuperado de http://repositorio.bc.ufg.br/handle/ri/15755.

Osório, L. C. (1997). A família como grupo primordial. Como trabalhamos com grupos. Porto Alegre, RS: Artes Médicas.

Pinheiro, T. (1995). Algumas considerações sobre o narcisismo, as instâncias ideais e a melancolia. Cadernos de psicanálise, 12 (15), 20-28. Recuperado de http://www.scielo.br/scielo.php?script=sci_arttext\&pid $=$ S1415-47142004000100009.

Pinheiro, M. T. da S., Quintella, R. R., \& Vertzman, J.S. (2010). Distinção teórico-clínica entre depressão, luto e melancolia. Psicologia clínica, 22(2), 147-168. Recuperado de http://www.scielo.br/pdf/pc/v22n2/10.pdf.

Taborda, L. P. D. R. (2017). Sofrimento psíquico de mães de crianças com câncer e a escuta do irrepresentável. Trabalho de conclusão de curso, Instituto de Psicologia, Universidade Federal do Rio Grande do Sul, UFRGS, Porto Alegre, RS. Recuperado de https://www.lume.ufrgs.br/ handle/10183/169481.pdf.

Submetido em: 1-6-2020

Aceito em: 27-1-2021 